\title{
Evaluating Marketability of Ten Selected Cultivars of Mango
}

\author{
Seyed Morteza Zahedi' ${ }^{1}$, Zahra Sadat Asgarian², Farzad Kian Ersi' ${ }^{3}$, Azar Seydi ${ }^{4}$ \\ ${ }^{1}$ Young Researchers and Elite Club, Karaj Branch, Islamic Azad University, Karaj, Iran \\ ${ }^{2}$ Department of Horticultural Sciences, Bu-Ali Sina University, Hamedan, Iran \\ ${ }^{3}$ Young Researchers and Elite Club, Hamedan Branch, Islamic Azad University, Hamedan, Iran \\ ${ }^{4}$ M.Sc. Agricultural and Natural Resources Research and Education Center, Ilam, Iran \\ Email: S.M_Zahedi@Yahoo.com
}

Received 24 February 2016; accepted 8 April 2016; published 11 April 2016

Copyright (C) 2016 by authors and Scientific Research Publishing Inc.

This work is licensed under the Creative Commons Attribution International License (CC BY). http://creativecommons.org/licenses/by/4.0/

c) (i) Open Access

\begin{abstract}
Mango is one of the most popular fruits in the world due to its attractive color, delicious taste, and excellent nutritional properties. Mango is among the most economically and culturally important tropical fruits. Mangos have become a standard food crop in south Iran. Quality determination of fruits is at present characterized by the overwhelming use of sensory. Quality indices include primarily external properties, such as appearance, size, shape, colour, texture, and flavour. Mangoes are rich in antioxidants. Antioxidants are really necessary for human diet and a healthy and longer life. Numerous phytochemicals are present in mango peel and pulp, such as the triterpene, lupeol which is under basic research for its potential biological effects. Thus high quality will attract people to the high consumption of fruits. Cultivars prepared with the origin of the Iran, India, Pakistan, and the Philippines. In this study, 10 cultivars were compared in terms of some indicators of quality in Ahvaz. One of the mango quality evaluation methods is sensory laboratory evaluation (panel test). This research carried out at 2013 in Chamran University, Ahvaz, Iran. The result indicated that the most quality was related to Alphonso cultivar. On this basis, fruit features such as mango flesh and skin color are an important component role in consumer acceptability.
\end{abstract}

\section{Keywords}

Control, Marketability, Sensory Laboratory Evaluation

\section{Introduction}

Mangos belong to the genus Mangifera of the family Anacardiaceae. The genus Mangifera contains several spe- 
cies that bear edible fruit. Most of the fruit trees that are commonly known as mangos belong to the species Mangifera indica. The other edible Mangifera species generally have lower quality fruit and are commonly referred to as wild mangos [1]. The mango, Mangifera indica L., is well known for its excellent exotic flavour and usually referred to as the king of fruit. It is a popular and economically important fruit, widely cultivated in the tropics and subtropics. The fruit is eaten fresh and in several other by-products, including juices, nectars, and purees. Commercial mango production is reported in more than 87 countries. The prominent mango producing countries are India, China, Thailand, Indonesia, Philippines, Pakistan and Mexico [2].

Fruits and vegetables play a significant role in human nutrition, particularly as sources of vitamins, minerals, dietary fibre and antioxidants. Consumption of a variety of fruits and vegetables on a daily basis is highly recommended because of associated health benefits, which include reduced risk of some forms of cancer, heart disease, stroke and other chronic diseases. Processing technologies have been developed for a few fruits, while a number of processing technologies are still under development. Given the high perishability of fruits and vegetables and the absence of proper processing and storage facilities, there is a wide price variation along the producer-consumer chain [3].

Mango fruit contains different classes of phytochemicals such as polyphenols, ascorbic acid and carotenoids, revealing health promoting properties mainly due to their antioxidant properties. Polyphenols, gallic acid, gallotannins, mangiferin, quercetin, kaempferol, p-OH-benzioc acid, m-coumaric acid, p-coumaric acid and ferulic acid were reported in mango flesh [4].

There are many hundreds of named mango cultivars. In mango orchards, several cultivars are often grown in order to improve pollination. Many desired cultivars are monoembryonic and must be propagated by grafting or they do not breed true. A common monoembryonic cultivar is "Alphonso", an important export product, considered as "the king of mangoes".

Cultivars that excel in one climate may fail elsewhere. For example, Indian cultivars such as "Julie", a prolific cultivar in Jamaica, require annual fungicide treatments to escape the lethal fungal disease anthracnose in Florida. Asian mangoes are resistant to anthracnose.

Generally, ripe mangoes have an orange-yellow or reddish peel and are juicy for eating, while exported fruit are often picked while underripe with green peels. Although producing ethylene while ripening, unripened exported mangoes do not have the same juiciness or flavor as fresh fruit.

Safety and quality standards for imported and processed foods are enforced by many importing countries. Local exporters must, therefore, conduct inspection, testing and certification for their export commodities. Many of these services are not available in Iran. Exporters are therefore dependent on costly foreign sources for these services. Existing laboratories and testing facilities are inadequate to maintain a high export and domestic standard. The cost of analysis for pesticides residues is prohibitive, and unaffordable to the common trader or even the exporter.

A number of studies on the processing and marketing of agricultural produce including fruits and vegetables have been conducted in Iran. Research conducted on mango marketing revealed that the share of the producer in the final price varies between $36 \%$ and $40 \%$. According to finding different varieties showed a variation in the critical temperature which lies between $40^{\circ} \mathrm{F}-45^{\circ} \mathrm{F}$ and wastage due to chilling may be avoided by keeping the fruits above this range [5] for this reason, rapid consumption, processing and marketing is important. A quality characters such as color, sweets, and pickle are one of the main sensory parameters for food quality and greatly influence consumers' preferences and quality perception [6]. In mango, features appearances play a significant role in the perception mango quality and overall acceptability.

\section{Materials and Methods}

Evaluation of plant growth and yield parameters: mangoes were harvested (mangoes were picked when ripe or almost ripe) and standard procedures were adopted for recording the data on yield and yield components. Vegetative growth parameters measured included plant height, time of fruit ripening and growth habit. Reproductive growth parameters measured were fruit weight recorded.

The varieties used in this experiment included: Alampur Baneshan, Almaas, Banganapalli, Neelam, Shan-eKhuda, Moshk, Mulgoba, Bombay, Alphonso, Kalak1.

Sensory evaluation by consumer panel: In this experiment, we used 35 consumer panelists for Sensory evaluation based on qualitative characters. Consumers were provided with a list of definitions of each sensory attribute and evaluations were made using a 10-point scale anchored with low (1) and high (10) intensity of each 

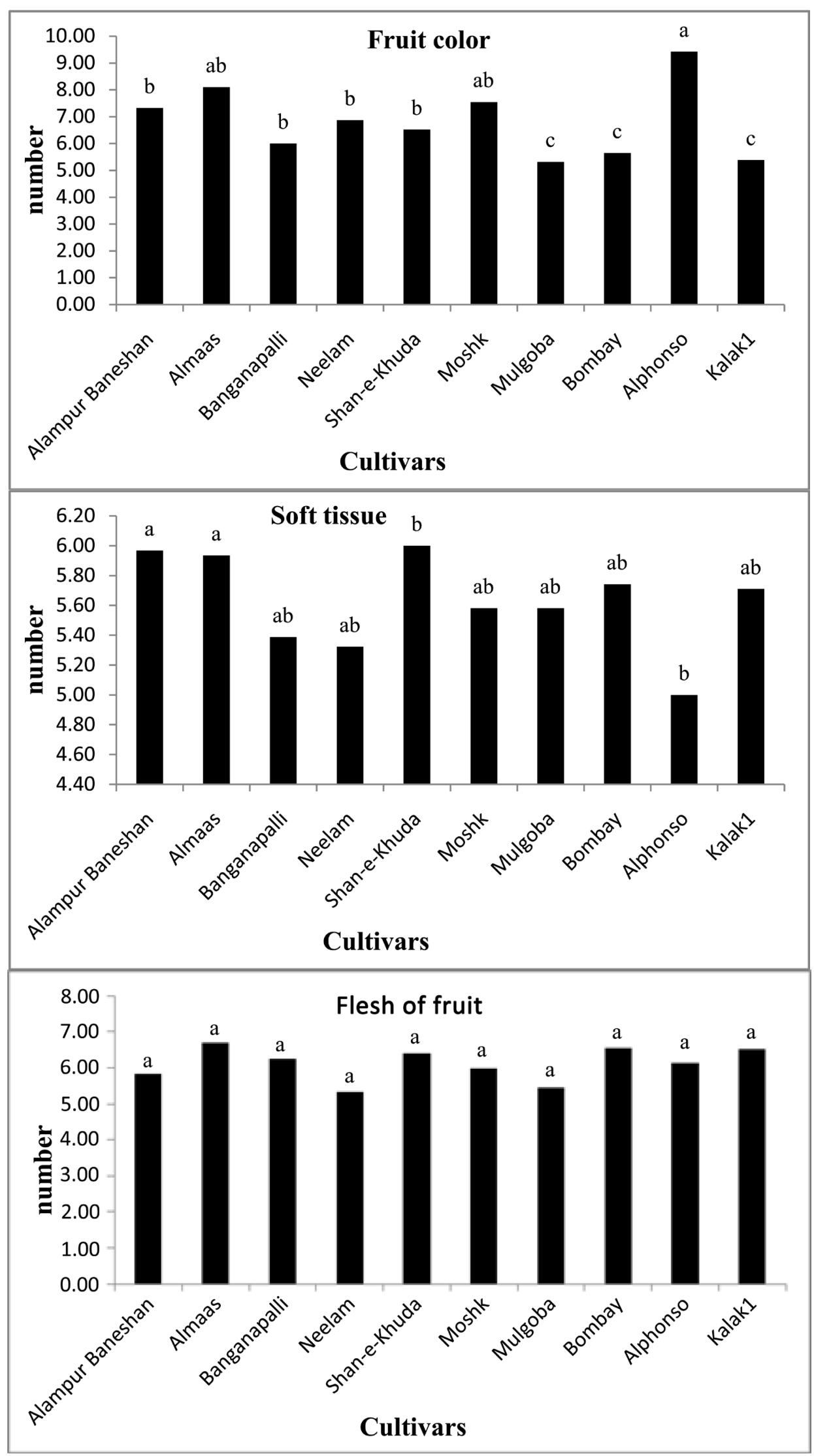


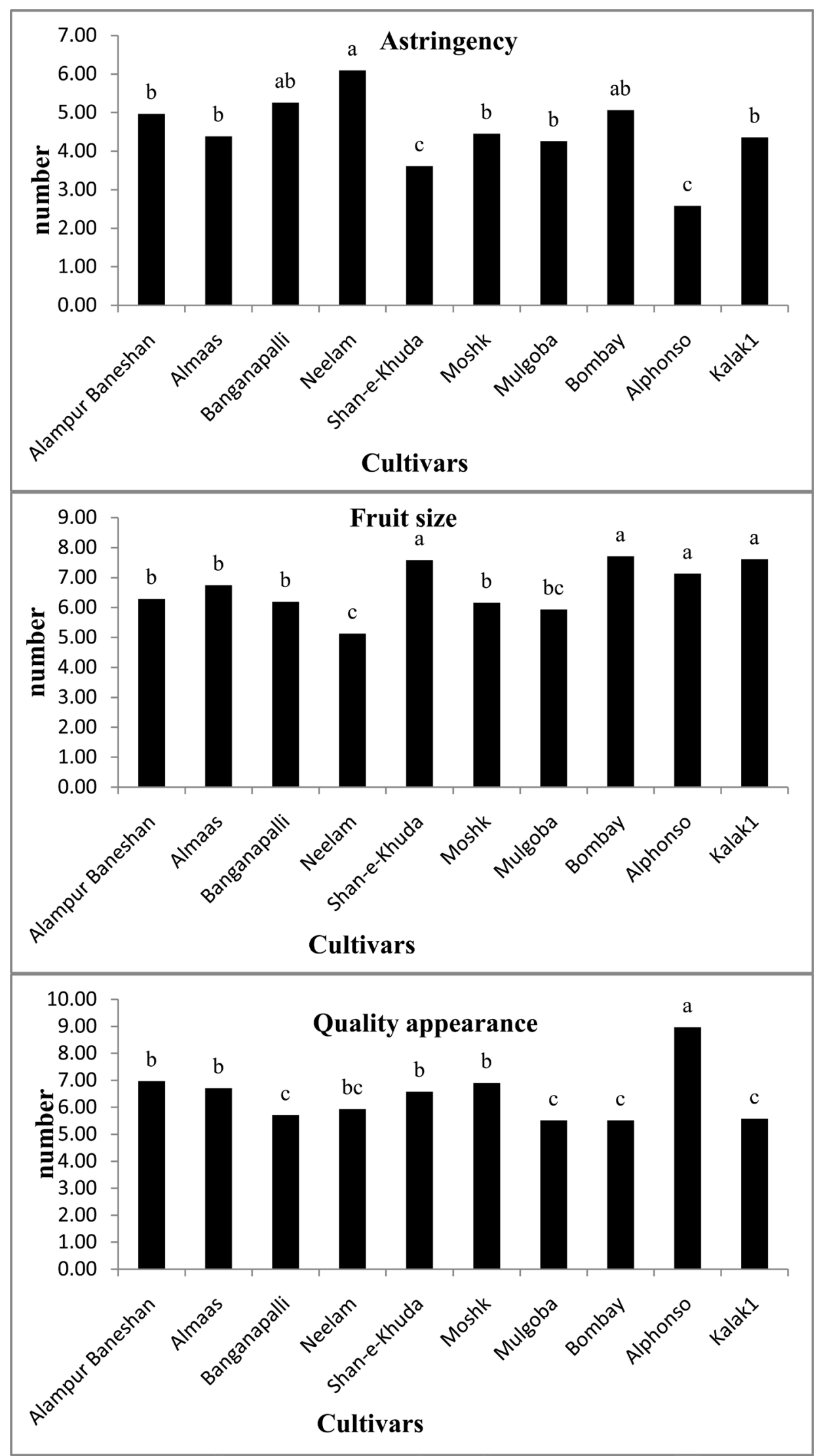




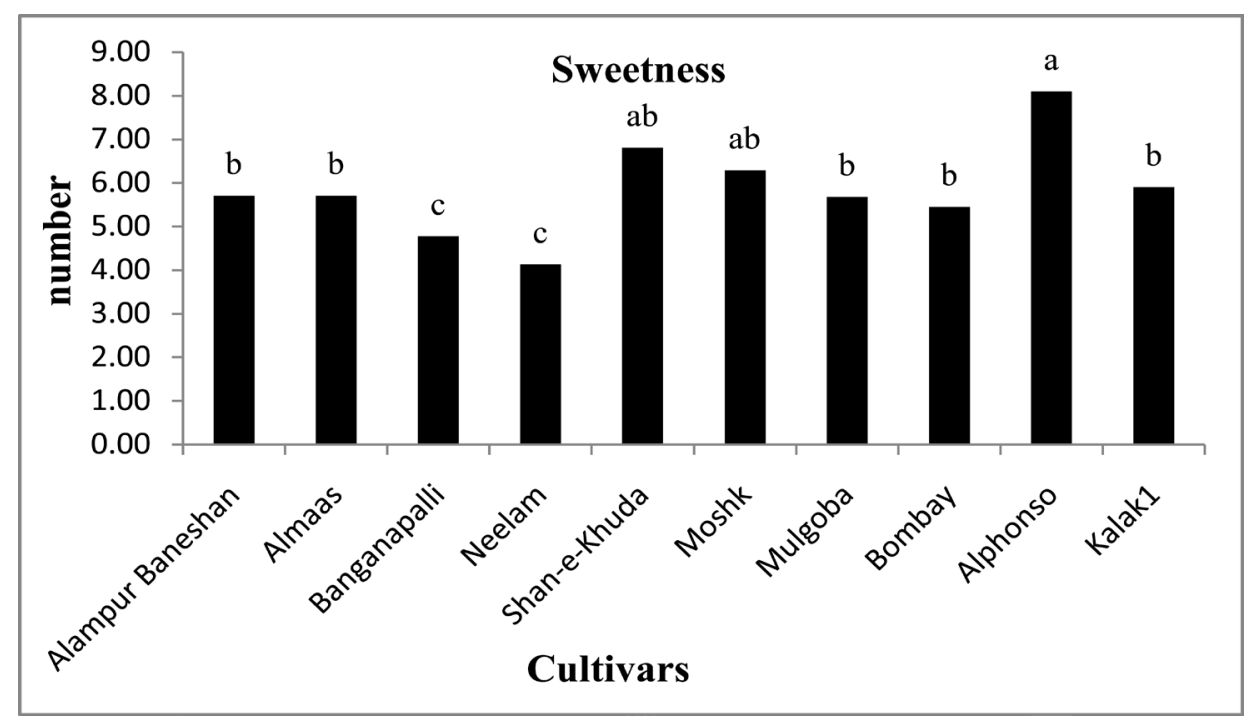

Figure 1. Sensory evaluation by consumer panel.

attribute. Consumers were first asked to intensity of appearance attributes of fruity, color, and size, and were then asked about Internal and Taste features.

Data analysis: The consumer panel data were analyzed using a mixed-effects ANOVA model holding the panelists as a random effect. ANOVA analyses were performed using SAS (SAS Inst., Inc., version 9.1; Cary, N.C., U.S.A.). Where appropriate, separation of the means was accomplished using Tukey's HSD. Principal components analysis (PCA) with no rotation was performed using XLSTAT. The significance value for all analyses was established as $\mathrm{P} \leq 0.05$.

\section{Results and Discussion}

The results indicated that significant differences appeared among the cultivars in all the characters of mango. There were significant differences in yield and yield components among cultivars (data are not shown).

Qualitative assessment results showed that Alphonso was better than other varieties in the pickled fruit characters surface quality fruit. Alphonso mangoes are often discussed as a popular cultivar. Alphonso mango is a seasonal fruit, considered to be among the most superior varieties of the fruit in terms of sweetness, richness and flavour. Alphonso mangoes have a rich, creamy, tender texture and are low in fibre content, with a delicate, creamy pulp. These characteristics make Alphonso one of the most demanded cultivars. The skin of a fully ripe Alphonso mango turns bright golden yellow with a tinge of red which spreads across the top of the fruit. The flesh of the fruit is golden saffron colour. In this study, one variety Alphonso was equally acceptable to the panelists as was evident from the results shown in Figure 1. Alphonso mango is known as the "king of mango" because of its delicious tropically fruity sweet taste and juicy saffron/golden coloured non-fibrous tender texture of its flesh. It has a significantly thinner more shiny skin. The Alphonso mango was introduced to India in Goa by "Afonso De Albuquerque", a Portuguese explorer and military strategist who led many Portuguese invasions into India in 15th century A.D. Over time, these Alphonso mango plantations spread from Goa to different places in Maharashtra as well as southern India along India's western coast. In this experiment, Alphonso had the best features.

Quality, i.e., the degree of excellence or superiority, of fresh fruits and their products is a combination of attributes, properties, or characteristics that gives each commodity value in terms of human food. The current study was aimed to facilitate the growers, exporters and government authorities to export mango varieties that would be well perceived by the consumer all around the world. The information derived from the present research would also assist the local fruit industry to select mango varieties for the production of various fruit products that impart highly acceptable sensorial attributes.

\section{References}

[1] Bally, I.S.E. (2006) Mangifera indica (Mango). Species Profiles for Pacific Island Agroforestry, 1-25. 
[2] Sivakumar, D., Jiang, Y. and Yahia, E.M. (2011) Maintaining Mango (Mangifera indica L.) Fruit Quality during the Export Chain. Food Research International, 44, 1254-1263. http://dx.doi.org/10.1016/j.foodres.2010.11.022

[3] Badrud-doza, A.F. (2006) Postharvest Management of Fruit and Vegetables in the Asia-Pacific Region. Asian Productivity Organization, Tokyo, Japan.

[4] Talcott, S.T., Moore, J.P., Lounds-Singleton, A.J. and Percival, S.S. (2005) Ripening Associated Phytochemical Changes in Mangoes (Mangifera indica) Following Thermal Quarantine and Low Temperature Storage. Journal of Food Science, 70, 337-341. http://dx.doi.org/10.1111/j.1365-2621.2005.tb09963.x

[5] Sundararaj, J.S. Muthuswamy, S. and Sadasivam, R. (1972) Storage of Mango Fruits. Symposium on Mango and Mango Culture. ISHS Acta Horticulturae 24. http://dx.doi.org/10.17660/actahortic.1972.24.53

[6] Calvo, C., Salvador, A. and Fiszman, S.M. (2001) Influence of Colour Intensity on the Perception of Colour and Sweetness in Various Fruit-Flavoured Yoghurts. European Food Research and Technology, 213, 99-103. http://dx.doi.org/10.1007/s002170100359 